\title{
On Sustainable eParticipation
}

\author{
Francesco Molinari \\ University of Siena, Dipartimento di Studi Aziendali e Sociali \\ Piazza S. Francesco 8, 53100 Siena, Italy \\ mail@francescomolinari.it
}

\begin{abstract}
Among the various analytical dimensions purporting to an appraisal of the replication potential of eParticipation projects, institutional factors deserve considerably more attention by theorists and practitioners alike. This paper introduces a "process oriented" definition of sustainable eParticipation, based on five key attributes: juridical compliance, legitimacy, social value, efficiency, and productivity. These can be used to assess the level of potential integration of a participatory practice or trial within the legal, political, social and organisational contexts of the public sector institutions involved. We posit that sustainable participation will emerge whenever these five dimensions are not jeopardised, compromised, or are left unaltered, by the introduction of participatory elements into any decision-making process regarding issues of public relevance. Empirical investigation is recommended to assess the impact of specific Preparatory Actions on eParticipation by using the five propositions introduced.
\end{abstract}

Keywords: Sustainability, Impact, eParticipation, Public Decision-Making, Appraisal.

\section{Introduction}

Over the last decade, a significant increase in the number, variety and quality of ICT supported political participation (henceforth: eParticipation) trials has become quite notable, particularly in Western and Southern European countries. In retrospect, the impulse of the European Parliament and the financial support by the Commission have had big merits in establishing a pan-European community of practice, made up of academia, governments and solution providers from virtually all countries of the Union $^{1}$.

Sound progress has been made since the European Commission started to support this emerging research strand under the $5^{\text {th }}$ and $6^{\text {th }}$ Framework Programmes in the ICT domain. Or since 2005, when the Parliament invited the Commission to launch a Preparatory Action on eParticipation, which is now counting on over 20 multinational projects and a coverage of two thirds of the EU countries [15]. While these initiatives

${ }^{1}$ This is mirrored by two specific initiatives sponsored by the European Commission, the PEPNET Thematic Network of Practitioners (http://pep-net.eu) and the MOMENTUM eParticipation Coordination Action (http: / / ep-momentum. eu). 
are mostly "owned" by national or local public authorities as prime motors and ultimate addressees of such "top-down" experiments, there is also evidence of a fast growth of "bottom-up" eParticipation, being driven by citizens and private sector blogs and social networks [18]. This whole scenario seems to support the view of ICT enthusiasts that electronic participation can bring a higher number of people back again to the democratic arena, particularly at local level, the dimension where most political and administrative processes actually take place ${ }^{2}$.

Though no pan-European collection of cases currently exists, available evidence on the "success stories" of eParticipation is receiving a great deal of attention from both practitioners and researchers in various European countries, as reflected by the many conferences and seminars that are taking place every year and a number of scientific articles and volumes that are being written to analyse this phenomenon. However, on the evaluative side, the results of most projects that have reached a closure apparently stay below the expectations that accompanied their start-up. The most evident limitations are twofold:

- The first one is implied by the number of active participants in the electronic trials, which is typically very low, and in any case not statistically representative, nor amenable to representation, of the underlying target group, not to speak of population as a whole [7];

- The other relates with the relatively poor impact of the (majority of) projects and achievements on the underlying decision-making process of the governmental agency involved. This issue has been usually referred to as the sustainability of eParticipation ([3], [11]).

Both issues are obviously interrelated, as for example, a low interest shown by the public in a given project will most likely reduce its impact, while on the other hand, the experimental nature of most eParticipation projects, which are innovating both on the technological and the methodological viewpoint, seems a compelling argument against the use of merely quantitative criteria to evaluate the impact of the trials completed. However, given the high interest stirred and the encouraging results of most projects in several participation areas, an answer is called for to a key question: is all this just a passing fad or does it evoke a permanent change, driven by ICT, in the C2G (Citizens to Governments) interaction?

In this paper, we contend that a positive answer to the above question largely depends on whether and to which extent the participatory process(es) designed might

${ }^{2}$ It's also worth mentioning the political impact of several Resolutions of the Council of Europe's Parliamentary Assembly, from No. 800 of 1983 ("Democracy atrophies without frequent participation by citizens who should, wherever possible, be consulted on matters closely concerning them, through appropriate mechanisms") through No. 980 of 1992 on citizens' participation in politics, up to No. 1121 of 1997 on the instruments of citizen participation in representative democracy. More recently, the Council of Europe's Committee of Ministers has issued several Recommendations to Member States, such as No. 19 of 2001 on the participation of citizens in local public life, No. 11 and 15 of 2004 on e-voting and egovernance, respectively, and the latest (No. 1 of 2009) on eDemocracy itself. http://www.coe.int/t/e/integrated_projects/democracy/02_activi ties/002_e\%2Ddemocracy/Recommendation\%20CM_Rec_2009_1E_FINAL_P DF.pdf 
"embed" into the preexisting system of governance of the public sector institutions involved. A more refined definition of sustainable eParticipation is then provided, which we have developed and tested in the context of one of the aforementioned Preparatory Actions, evolving from previous research done in the area $[1,2,4,19]$. Use of this definition is invoked as a further dimension, which we call of project appraisal, to the evaluative framework developed by [21, 22] with a main focus on used technologies, adopted methods and tools, and supported C2G interaction areas.

The remainder of this paper goes as follows: Section 2 summarizes the antecedents of using the sustainability concept in the evaluation literature in general, and in the specific domain of eParticipation assessment in particular. Section 3 highlights the role of institutional aspects in the shaping of participation and locates the discourse on sustainability in the framework introduced by previous literature. Section 4 overviews a specific implementation example, making reference to the system of governance in the Italian Region of Tuscany. Section 5 discusses the implications of the above case, in terms of a "process oriented" definition of sustainable eParticipation, based on five attributes: juridical compliance, legitimacy, social value, efficiency, and productivity. Section 6 includes some conclusions and recommendations for future work.

\section{Sustainability as an Evaluative Concept}

Generally speaking, sustainability is an important criterion to assess the results of any project/programme $(\mathrm{P} / \mathrm{P})$. In the evaluation literature ${ }^{3}$, sustainability analysis usually focuses on the following six dimensions (see also Figure 1):

1. Stakeholders' Ownership: or the actual level of sharing of the objectives and achievements of the $\mathrm{P} / \mathrm{P}$ by the stakeholders involved;

2. Institutional Compliance: or the extent to which the $\mathrm{P} / \mathrm{P}$ is "embedded" in the organisational/regulatory structures of the community;

3. Financial Autonomy: whether the $\mathrm{P} / \mathrm{P}$ is likely to continue after the end of funding; whether enough funds are available to cover all costs; whether the costs are likely to be borne after the funding ends;

4. Socio-cultural Integration: whether the $\mathrm{P} / \mathrm{P}$ takes into account the local perception of needs and respects participants and beneficiaries cultures and beliefs; whether and how the changes induced by the P/P can be accepted by the stakeholders involved;

5. Technical Feasibility: or the extent to which the technology and knowledge provided fit into the existing skills and infrastructure available to participants; whether beneficiaries are likely to operate and maintain the technology acquired without further external assistance;

6. Continuity Over Time: or the concrete possibility of extending or replicating successfully the $\mathrm{P} / \mathrm{P}$ at hand or other similar interventions.

\footnotetext{
${ }^{3}$ Following Elliot Stern (quoted in [20]), by evaluation we intend "any activity that, throughout the planning and delivery of innovative programmes, enables those involved to learn and make judgments about the starting assumptions, implementation processes and outcomes of the innovation concerned". Referenced sources of this paper include: $[5,6,8,10]$.
} 


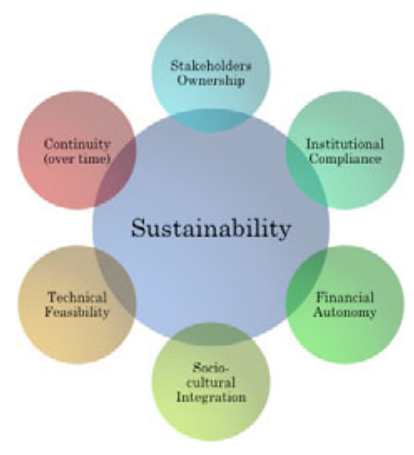

Fig. 1. The six dimensions of sustainability

Not surprisingly, sustainability evaluation looks like a complex task with multifaceted dimensions; it is also strictly related with impact analysis, as they both deal (among other aspects) with the likely or foreseen effects of the $\mathrm{P} / \mathrm{P}$ in the medium to long term. These effects are - by definition - going beyond the results produced and/or the benefits induced within the P/P's scheduled life, and this is why they are normally defined outcomes rather than outputs.

Impact and sustainability assessment is thus related with the progress of time. It wouldn't make sense to try and evaluate these in the same way as we might want to do with relevance, a criterion mostly utilized at the design stage, or with efficiency and effectiveness, which can be best demonstrated after implementation or right at the end of the $\mathrm{P} / \mathrm{P}$, using information derived from its internal budget or other accounting evidence.

Finally, sustainability is also extensively mentioned in literature as an evaluation criterion of eParticipation trials. Though it may look tautological, this is mostly seen as an approach to detecting the barriers to continuity or replication over time of a successfully achieved pilot ([2], p. 23). In fact, as the same scholars ([2], p. 11) stated: "eParticipation in practice can still be characterised as 'experimental' or 'pilot'. Sustainable eParticipation is rarely achieved...". Likewise, in their analysis of barriers, challenges and needs of eParticipation research, others ([4], p. 29) noted that: "We need to move to an environment and culture where there is clear commitment and willingness of political and administrative representatives to engage with eParticipation". By a similar vein, ([1], p. 12) locate sustainability among the key aspects to be analysed while evaluating an eParticipation project. Some attributes in focus coincide with the qualifications of sustainability offered in a seminal work by [8]. Likewise, ([19], p. 13) define the process of sustainability assessment as: "The detection of operational and policy barriers in order to ensure the continuity of a case without creating any disharmony and imbalance in a system". Taking inspiration from the Stockholm Challenge Award ${ }^{4}$, the same authors qualify and integrate this definition, by adjoining sustainability to the 'future development' concept.

To summarise, we can tentatively map the surveyed pieces of research on the evaluation of eParticipation sustainability to the six conceptual dimensions listed at the beginning of this section, as displayed by the following Table:

${ }^{4}$ http: //www.stockholmchallenge.se/evaluation-criteria 
Table 1. Key dimensions of eParticipation sustainability

\begin{tabular}{|c|c|c|c|c|c|}
\hline Dimension & Source & {$[2]$} & [4] & [1] & [19] \\
\hline Stakeholders' Ownership & & $\sqrt{ }$ & $\sqrt{ }$ & $\sqrt{ }$ & $\sqrt{ }$ \\
\hline Institutional Compliance & & & $\sqrt{ }$ & & $\sqrt{ }$ \\
\hline Financial Autonomy & & & & $\sqrt{ }$ & $\sqrt{ }$ \\
\hline Socio-cultural Integration & & $\sqrt{ }$ & $\sqrt{ }$ & $\sqrt{ }$ & \\
\hline Technical Feasibility & & $\sqrt{ }$ & & $\sqrt{ }$ & $\sqrt{ }$ \\
\hline Continuity Over Time & & $\sqrt{ }$ & $\sqrt{ }$ & $\sqrt{ }$ & $\sqrt{ }$ \\
\hline
\end{tabular}

As Table 1 shows, sustainability is mostly associated with stakeholders ownership, as well as with continuity over time of the eParticipation trials. However, there is no demonstrated link between these two dimensions, or at least not a stronger one than with any possible alternative displayed.

Furthermore, such a descriptive approach leaves partly unattended what the proper means should be to ensure that the ultimate goal of replication is actually achieved. In other words, it would be appropriate to turn the above instances of the sustainability concept, from evaluation into appraisal dimensions: where the notion of appraisal ${ }^{5}$ refers to the process of assessing, in a structured way, the case for proceeding any further with a proposed method, channel or tool for electronic Participation.

\section{Sustainability as an Appraisal Criterion}

Recently, [21, 22] proposed a framework for assessing and scoping eParticipation projects focusing on the technologies used, the methods and tools adopted, and the $\mathrm{C} 2 \mathrm{G}$ interaction areas supported. According to its proposers, this framework lends itself to a twin assessment of eParticipation, reflecting on the one hand the suitability or appropriateness of ICT introduction into the democratic process, and on the other hand the actual degree of citizens' involvement in public decision-making. While this framework has evolved into various modeling attempts [23, 12] that produced some encouraging applications in the domain of descriptive analysis, its potential for project appraisal may have been overlooked, with particular respect to sustainability assessment. To highlight this latter aspect, we have matched the evaluation criteria presented in Section 2 with a simplified version of the framework, as shown by the following picture.

Proceeding from bottom to top, we observe that technologies, methods and tools, and $\mathrm{C} 2 \mathrm{G}$ interaction areas (that $[21,22]$ specifically call eParticipation areas), all undoubtedly pertain to the domains of $\mathrm{P} / \mathrm{P}$ design and implementation, in which the principal assessment criteria are the "standard" ones of relevance, efficiency and efficacy. In particular, since we (after [14]) normally refer to eParticipation as the use of ICT to enhance people's activism and citizens' involvement in public affairs, this level of analysis can be further refined by focusing on ICT role to enhance relevance and efficiency, and to the participatory techniques used in the trial as a means towards

${ }^{5}$ http://en.wikipedia.org/wiki/Project_appraisal 


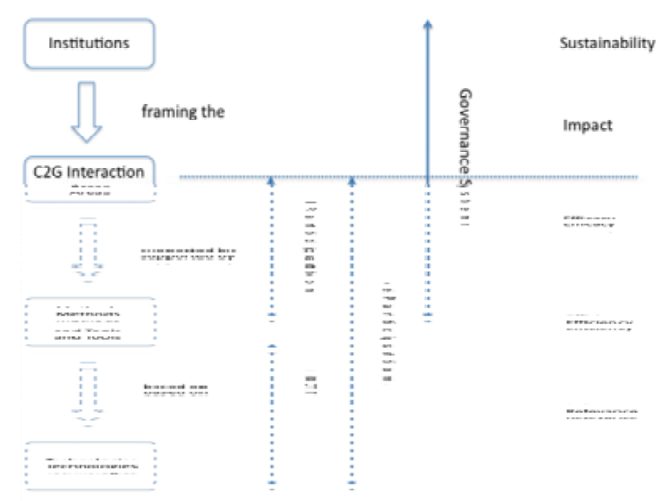

Fig. 2. A framework for eParticipation appraisal

increased efficacy. However, what is important to stress in this perspective is that the institutional dimension (or what we call the governance system) looks like the only appropriate realm for impact and sustainability appraisal.

Put in this way, the message seems quite clear: staying below the dotted line, i.e. at the level of eParticipation (stricto sensu, i.e. political participation + ICT usage), we can only evaluate the relevance, efficiency and efficacy (or effectiveness) of a project, or trial thereof. If we want to approach the more challenging task of assessing impact and sustainability, we will have to scale up to the level of the governance system itself. Like any social system, this is made up of actors (individuals, such as policy makers, but also collective bodies, like political parties, business associations, trade unions, voluntary organisations and other stakeholders) and institutions (e.g. laws, regulations, traditions, cultural and social norms). Notice that democratic processes, as defined by [22], are an integral part of the governance system themselves. Now, the interaction and the reciprocal links among actors are at least framed, and ultimately shaped, by the structure and profile of institutions en force ${ }^{6}$. This seems particularly the case of the $\mathrm{C} 2 \mathrm{G}$ interaction areas, where both "offline" and "online" participation trials typically materialise (for instance: urban planning, public sector budgeting, climate change policy, and so on).

\section{The Tuscany Case}

To make an example of how institutions can actually shape participation, it is worth mentioning the case of the Tuscany Region in Italy.

In the last ten years, the Regional Government of Tuscany, under the pressure of national level constitutional reform, has undergone a quite complex transformational pathway, aimed at migrating from traditional consultation and concertation with local

${ }^{6}$ Of course, it can also be vice versa, which is not relevant, however, to the flow of our analysis, located in the short-to-medium run where existing institutions may be taken as invariant with respect to the outcomes of $\mathrm{C} 2 \mathrm{G}$ interaction. 
stakeholders (business associations, trade unions, and lower-tier public authorities) meant to involve the private and public sector of the Region into the various instances of strategic programming and implementation - towards proper participation of the citizens in the process of legislation, regulation and more generally, public decision-making.

Historically, the Tuscan model of Cooperative Governance, first established by the Regional Law No. 49 of 1999, held several degrees of analogy with the EU Multilevel Decision Making system: a metaphor increasingly used by the academics to highlight the fact that many different levels of authority - from the central to the peripheral - are involved in public decisions on "key" policy issues, as well as the various local actors (including non-governmental ones) that might somehow be affected by the decisions to be taken.

In 2007, this model was integrated by the approval of the first Regional bill in Europe dealing with the topic of participation in public decision-making (Tuscany's Law No. 69). In particular, art. 20 of Law No. 69 added to art. 10 of Law No. 49/1999 the following paragraph: "2 bis. Regional plans and programmes must specify the share of available resources dedicated to the organisation of participatory processes and to be determined on a sufficient basis to guarantee their effective fulfilment; participation in the regional plans and programmes is promoted exclusively by the Regional Government". The next articles of Law No. 69 further specify the policy domains where the establishment of participatory processes has become mandatory. These include: Regional Law No. 1/2005 in the topic of urban planning; Regional Law No. 40/2005 regarding the universal health service; Regional Law No. 41/2005 on social citizenship rights; Regional Law No. 25/1998 regarding the management of waste disposal; Regional Law No. 1/2004 on the development of information society.

Under the provisions of the above set of Regional Laws, the outline of a typical, "standard" decision-making process could be depicted as per the following diagram.

The process stages highlighted in the "Involvement" boxes encompass the classical "four levels" of the (traditional and/or electronic) Governance model first introduced by $[16,17]$ - namely:

- Information dissemination, or the distribution of information that is complete, objective, reliable, relevant, easy to find and to understand;

- Consultation, or the involvement of citizens and stakeholders in a joint exercise that has clear goals and rules, defining both its limits and the government's obligation to account for the use of its results;

- Concertation, or a more advanced interaction than simply feedback provision as for the case of consultation; dealing with negotiation and mutual composition of confronted interests;

- Active participation, or the proper integration of citizens' will and "wisdom" into government's decision-making.

Curiously enough, while the diagram below can well be conceived of as a process, structured and detailed by a number of Regional laws and regulations, most activities in the process are still carried out "offline" (for instance, the management of meetings with local stakeholders), or at best through several independent Web 1.0 applications (e.g. Regional government's sectorial portals): in either case, no or little effort has been done so far towards a unitary view - supported by advanced ICT applications of the integrated and interlaced nature of the various process stages. 




Fig. 3. AS-IS policy-making process in the Tuscany Region ${ }^{7}$

In short, what we are facing here is a kind of mismatch between availability and usage of process technology in public administration. This can become increasingly evident in the years to come, where the Region itself foresees the involvement of an increasing number of people into shared decision making on a growing variety of policy processes. The rationale for that is still related to the Regional Law No. 69 of 2007, which recognizes and guarantees to everyone (including foreigners) the right to participate in public sector's decision-making. Under the provisions of the Law, any citizen, association or institution located in Tuscany may request the activation of a participatory process on major investment projects, development programmes and initiatives, of regional and/or local relevance. There are three dates during a year, by which citizens can submit such a request: March and July $31^{\text {st }}$, and November $30^{\text {th }}$. The outcome of the public debate is not binding, but the process must be finalised in 6 months time only. If the majority of public opinion is against, those who brought the project in may waive it or support a different version, or insist on the original formulation providing appropriate reasons thereof. In any case, a more informed decision from the competent authority will be allowed and certainly, if the debate has been lively and participated, it would be hard for a public body not to take its results into account.

Thus, the Regional Law, which has become fully operational by early 2009, with the appointment of the Regional Authority on Participation and the start-up of the first participatory processes launched under its provisions, aspires to open up a "third way" between participatory and representative democracy, through a more intense involvement of citizens on a discussion and deliberation about the "big issues" of public interest, avoiding any waste of time in the process and possibly any protests after the political decisions are finally taken.

Currently, the Regional Government envisages to setup and experiment on a multichannel decision-making support environment that could ultimately involve all key stakeholders and the entire Tuscan population (approx. 3,6 million people from 287 municipalities), in compliance with the provisions of Law No. 69/2007. In this

\footnotetext{
${ }^{7}$ Adapted from: Regional Cabinet decision No. 2 of $6^{\text {th }}$ November 2006.
} 
scenario, several eParticipation methods and tools can be used, where co-location and co-presence of participants during the consultations, discussions and deliberations are becoming less important, while the delivery and exchange of multimedia (text, audio and video) information is enhanced, thanks to the ubiquity and usability of devices and applications employed.

\section{Discussion}

What are the implications of our framework and case description for the definition and appraisal of sustainable eParticipation? In order to highlight them, we would like to borrow a definition of sustainability originally provided by [13], that is "the ability of an ecosystem to maintain (its) ecological processes and functions, biodiversity, and productivity over time". Adapting it to our perspective, this becomes the ability of a participatory decision-making process to maintain juridical compliance, legitimacy, social value, efficiency and productivity over time.

Why is this definition different from the previously commented ones? First, it does not focus on eParticipation as such. We don't even speak of electronically supported interactions between citizens and governments; our attention particularly goes to the implications arising from the addition of (offline and/or online) participation to stateof-the-art legislative, regulatory or policy-making processes (workflows). In fact, as it emerges from the Tuscan experience, either a discontinuous change in the existing system of governance occurs, or even the best performing (e-)Participation trial or practice will remain 'experimental' or 'pilot' forever. On the other hand, what needs to be further explored is the set of conditions under which a migration from 'selfreferential' to 'inclusive' (or 'participatory') decision-making may not endanger the stability of the underlying political and administrative environment. Thus, making institutional change an option that at least in principle, could be considered as viable and ultimately sustainable.

Secondly, while an element of 'continuity over time' is being kept in association with our new definition of sustainable participation, this avoids the partly tautological results surveyed in Section 2 and outlined in Table 1 above. Here, continuity refers to what has been called Institutional Compliance, namely, the possibility to "embed" the participatory methods and tools experimented into the legal, organisational, political and social infrastructures of a governance system. Being a multifaceted concept, that form of compliance can be split up into a variety of procedural attributes, namely five, which are introduced and described later in this Section.

What does this definition add up to the current evaluation research? First of all, we posit that relevant areas for sustainable institutional change in the public sector whether eParticipation related or not - cover the key process dimensions of juridical compliance, legitimacy, social value, efficiency and productivity over time. Whatever $\mathrm{P} / \mathrm{P}$ leaves these unchanged (if not improved), candidates itself to provide a positive contribution in that direction. In particular, we posit that sustainable participation will emerge whenever these five dimensions are not jeopardised, compromised, or are left unaltered, by the introduction of participatory elements into a given decision-making process regarding issues of public relevance. Empirical testing is recommended of these five aspects upon evaluation of every eParticipation project, as we expressly did 
for the sustainability assessment of our own Preparatory Action [9], when we tried to migrate away from a mere reporting of Project outcomes, and to acknowledge the long-term impact of the 'assets' generated on the overall governance system of each specific public sector authority involved.

In order to provide an operational description for each of the five dimensions of sustainability introduced, we propose to see them as attributes that clarify and specify the actual meaning of sustainability, much in the same way as in the literature on sustainable development the same term takes on different meanings according to the attributes adjoined to it ${ }^{8}$. Thus, in analogy to the notions of, say, juridical, ethical, or political sustainability of growth and development, we now introduce the following qualifying statements for the sustainability of eParticipation:

Juridical Compliance. A legislative or policy-making process is said to be juridically compliant whenever it can be fairly acknowledged by a neutral third party (in particular, at one extreme, by Administrative Justice) to lay beneath the scope and provisions of existing laws and regulations in the subject area addressed. A variant of the above statement - particularly apt to Common Law countries, such as the UK etc. - can make reference to a (weaker, yet more encompassing) compliance with the legal and/or statutory aims of a public sector organisation and/or with previous rulings of administrative Courts. From this set of references, a first attribute of sustainable participation can be derived: It is said to be sustainable a participatory decisionmaking process that is able to maintain its previous degree of juridical compliance unaltered.

Legitimacy. A legislative or policy-making process is said to be legitimate whenever it is approved by a majority of adult population (in particular, by a majority of the voters in general, either national or local, elections). To us, legitimacy has a different meaning with respect to juridical compliance. For instance, the opposing parties to a governing majority may find some or all of their decisions as lacking legitimacy, yet being able to demonstrate that they also break-up some existing norm (if not a Constitutional principle) is a totally different matter. Moreover, one of the key features of representative democracy is the political legitimisation of governments by means of periodic (free and transparent) elections. Nonetheless, more trust and better acceptance of ruling governments in the eyes of the citizens are often associated with the creation of more and better spaces for involvement in decision-making. From this definition, a second attribute of sustainable participation can be derived: It is said to be sustainable a participatory decision-making process that is able to increase the level of its political legitimacy over time.

Social Value. The concept of social value is broader than the one of social capital, as it also includes subjective aspects of citizens' well-being, such as their ability to participate in making decisions that affect themselves. Changes in social value may occur over time, because of e.g. changes in the dominant moral vision, the evolution of religious beliefs, changes in the economy, technological innovation, demographic

\footnotetext{
${ }^{8}$ See [13] and also http: / /www.ec.gc.ca/soer-ree/English/SOER/ 1996 report/Doc/1-5-2- 6-1.cfm
} 
shifts, scientific findings, etc. On the other hand, it is a known fact that communities able to engage their fellow citizens in activities of social relevance are also the most successful in reaching sustainable development targets ${ }^{9}$. In short, a legislative or policy-making process actually creates social value if it enhances collaboration and civic engagement of citizens and stakeholders. From this definition, a third attribute of sustainable participation can be derived: It is said to be sustainable a participatory decision-making process that is able to create more, or at least no less, social value than its previous (non participatory) instances.

Efficiency. It may sound odd that the notion of efficiency - already defined as the ratio between outputs (or results) of a $\mathrm{P} / \mathrm{P}$ and the inputs (or resources) that were necessary to support its activities ${ }^{10}$ - is now moved from the implementation to the evaluation stage. In fact, one of the known difficulties related to such concept is that neither the outputs, nor the inputs, of a given $\mathrm{P} / \mathrm{P}$ are all measurable quantitatively and/or by one common measurement unit. This is why we adopt here a stricter notion of efficiency, which is nonetheless particularly useful in highlighting the importance of achieving financial savings, or at least keeping costs invariant, by the integration of participation in the existing institutional framework ${ }^{11}$. Following this concept, a fourth attribute of sustainable participation can be derived: It is said to be sustainable a participatory decision-making process that is able to reduce operational costs or at least keep them invariant with respect to its previous (non participatory) instances.

Productivity. Formally speaking, productivity might appear the reverse of efficiency, i.e. the ratio between outputs and inputs of a P/P. Even in this case, we adopt a stricter notion that focuses on a specific aspect of public administration: the productivity rate of employees and managers ${ }^{12}$. Following this concept, a fifth attribute of sustainable participation can be derived: It is said to be sustainable a participatory decisionmaking process that is able to increase public officials' productivity over time.

Taken together, the two latter propositions underlie the fact that - without a clear advantage in terms of cost savings or productivity gains for the organisation involved - the success of eParticipation will continue to be mostly dependent on the sporadic prevalence of passionate idealists and/or ICT enthusiasts within existing communities of civil servants and elected officials.

${ }^{9}$ For example, the UK based project PatientOpinion

(http://www.patientopinion.org.uk) invites patients to comment, review and rate the services they have received at healthcare facilities and allow them comparing the reviews of other patients (like in several hotel booking portals).

${ }^{10}$ In short, working with greater efficiency means doing more with the same, or the same with less.

11 This can be done in many different ways: one good example is given by the US project entitled Peer-to-Patent (http://www.peertopatent.org), which has opened up to the general public's participation the patent examination process, thus reducing the delays in examining some applications.

12 Again, there are many possible ways to increase this: today, the so-called Web 2.0 applications are growingly used in the public sector, not only for "crowdsourcing" new ideas and contributions from the Internet population, but also as to support the capacity of civil servants to handle, assess, give response to citizens inquiries. 


\section{Conclusions}

The big challenge of future research and practice on eParticipation, is to assess the conditions under which civic engagement and citizens empowerment can become "embedded" components of new and more advanced (digital) governance systems.

In this paper, we have introduced a new and possibly more advanced definition of sustainable eParticipation, based on five fundamental dimensions, which can be used to assess the level of potential integration of a participatory practice or trial within the legal, political, social and organisational contexts of the public sector institutions involved. Empirical investigation is recommended to assess the potential of our model by testing the five propositions delineated above.

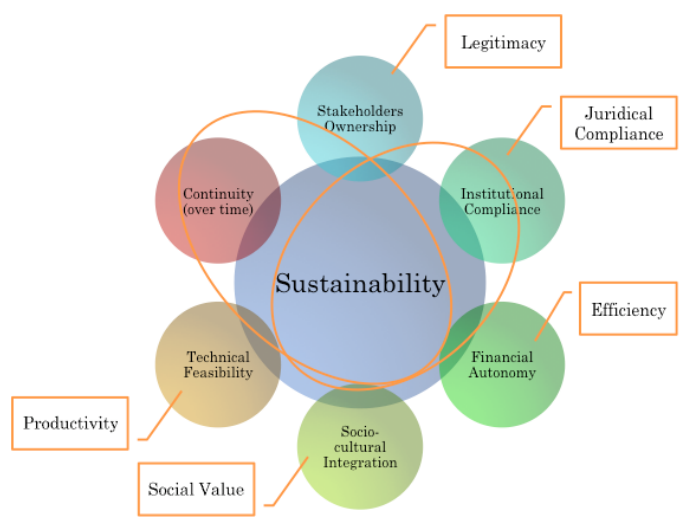

Fig. 4. New/Old Concept Mapping

Compared with Figure 1, reflecting the state of the art of theoretical reflections on sustainability, our new concept can be graphically represented as above.

Like the diagram shows, our definition takes on "continuity over time" as a central trait of sustainability, though with a different and less tautological meaning as it was explained in Section 5. Furthermore, it overlaps to the "institutional compliance" concept, leaving the remaining dimensions (also differently named) in a subordinate or explanatory position. We expect that the proposed taxonomy should be beneficial to future experiments (and evaluation thereof), being able to define and encompass all the different aspects of more direct relevance and impact for eParticipation designers and policy makers alike.

Acknowledgments. This research was made possible in part by a co-funding of the European Commission to the IDEAL-EU project, a Preparatory Action in the area of eParticipation. However, the opinions expressed in this paper are solely of the author and do not involve any of the EU institutions.

\section{References}

1. Aichholzer, G., Westholm, H.: Evaluating eParticipation Projects: Practical Examples and Outline of an Evaluation Framework. European Journal of ePractice 7 (March 2009) ISSN: 1988-625X 
2. Aichholzer, G., Allhutter, D., Freschi, A.C., Lippa, B., Macintosh, A., Moss, G., Westholm, H.: eParticipation Evaluation and Impact. DEMO-Net Project Deliverable No. $13.3(2008)$

3. Bicking, M., Wimmer, M.: eParticipation Projects Evaluation Methodology. MOMENTUM Deliverable No. 2.5 (2008),

http: / / www. ep-momentum.eu (accessed)

4. Coleman, S., Macintosh, A., Schneeberger, A.: eParticipation Research Direction based on Barriers, Challenges and Needs. DEMO-Net Project Deliverable No. 12.3 (2007)

5. Development Researchers' Network: Monitoring and Evaluation for NGOs Projects. A Manual for FORUM SOLINT, Forum Valutazione No. 14, pp. 105-173 (2002)

6. European Commission: Evaluation in the European Commission: A Guide to the Evaluation Procedures and Structures currently operational in the Commission's External Cooperation Programmes. Brussels, EuropeAid Evaluation Office (2001)

7. Ferro, E., Molinari, F.: Making Sense of Gov 2.0 Strategies: No Citizens, No Party. In: Proceedings of the eDEM09 Conference on Electronic Democracy, Vienna, Austria, September 7-8 (2009)

8. Henderson, M., Henderson, P.: Associates: E-democracy Evaluation Framework (2005) (unpublished manuscript)

9. IDEAL-EU Project Consortium: Deliverable D7.1 Sustainability Report (2009)

10. Interamerican Development Bank: Evaluation: A Management Tool for Improving Project Performance. IBD Evaluation Office (1997)

11. Islam, M.S.: Towards a sustainable e-Participation Implementation Model. European Journal of ePractice 5 (October 2008) ISSN: 1988-625X

12. Kalampokis, E., Tambouris, E., Tarabanis, K.: A Domain Model for eParticipation. In: Proceedings of the 3rd International Conference on Internet and Web Applications and Services (2008)

13. Kaufmann, M.R., Graham, R.T., Boyce Jr., D.A., Moir, W.H., Perry, L., Reynolds, R.T., Bassett, R.L., Mehlhop, P., Edminster, C.B., Block, W.M., Corn, P.S.: An ecological basis for ecosystem management. Fort Collins, Colorado: U.S. Department of Agriculture Forest Service, Rocky Mountain Forest and Range Experiment Station and Southwestern Region. USDA Forest Service General Technical Report RM-246 (1994)

14. Macintosh, A.: Characterizing e-Participation in Policy-Making. In: Proceedings of the 37th Hawaii International Conference on System Sciences (2004),

http: / / csdl2 . computer. org/comp/proceedings/hicss / 2004 / 2056/05/205650117a.pdf

15. MOMENTUM White Paper: Report on the Objectives, Structure and Status of eParticipation Initiative Projects in the European Union eParticipation Workprogramme (June 2009), http: / / www . ep-momentum. eu (accessed)

16. OECD: Citizens as Partners: Information, Consultation and Public Participation in Policymaking. OECD Publishing, Paris (2001a)

17. OECD: Engaging Citizens in Policy-making: Information, Consultation and Public Participation. OECD Public Management Policy Brief No. 10. (2001b), http: / / www. oecd.org/dataoecd/24/34/2384040.pdf (accessed)

18. Osimo, D.: Web 2.0 in Government: Why and How? JRC/IPTS Scientific and Technical Reports (2008) ISSN 1018-5593

19. Panopoulou, E., Tambouris, E., Tarabanis, K.: Framework for eParticipation Good Practice. European eParticipation Study Deliverable D4.1b, 2nd version (November 2008) 
20. Sommerlad, E., et al.: A guide to local evaluation. London, Tavistock Institute of Human Relations, Evaluation Development and Review Unit (1992)

21. Tambouris, E., Liotas, N., Tarabanis, K.: A Framework for Assessing eParticipation Projects and Tools. In: Proceedings of the 40th Hawaii International Conference on System Sciences (2007a)

22. Tambouris, E., Liotas, N., Kaliviotis, D., Tarabanis, K.: A Framework for Scoping eParticipation. In: Proceedings of the 8th Annual International Digital Government Research Conference (2007b)

23. Wimmer, M.A.: Ontology for an e-Participation Virtual Resource Centre. In: Proceedings of the ICEGOV2007, Macao, China, December 10-13 (2007) 